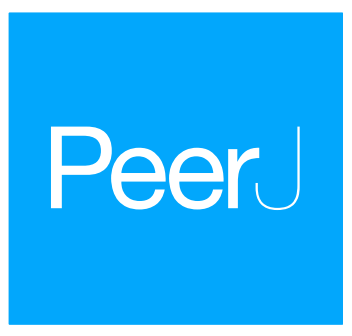

\title{
Change of niche in guanaco (Lama guanicoe): the effects of climate change on habitat suitability and lineage conservatism in Chile
}

\author{
Andrea G. Castillo ${ }^{1}$, Dominique Alò ${ }^{1,2}$, Benito A. González ${ }^{3}$ and \\ Horacio Samaniego $^{1}$ \\ ${ }^{1}$ Laboratorio de Ecoinformatica, Universidad Austral de Chile, Valdivia, Los Ríos, Chile \\ ${ }^{2}$ Pontificia Universidad Católica de Chile, Departamento de Ecología, Santiago, Chile \\ ${ }^{3}$ Laboratorio de Ecología de Vida Silvestre/Facultad de Ciencias Forestales y de la Conservación \\ de la Naturaleza, Universidad de Chile, Santiago, Chile
}

Submitted 5 January 2018

Accepted 15 May 2018

Published 28 May 2018

Corresponding author

Horacio Samaniego,

horacio@ecoinformatica.cl

Academic editor

Bruno Marino

Additional Information and Declarations can be found on page 16

DOI 10.7717/peerj.4907

(c) Copyright

2018 Castillo et al.

Distributed under

Creative Commons CC-BY 4.0

\section{OPEN ACCESS}

\section{ABSTRACT}

Background: The main goal of this contribution was to define the ecological niche of the guanaco (Lama guanicoe), to describe potential distributional changes, and to assess the relative importance of niche conservatism and divergence processes between the two lineages described for the species (L.g. cacsilensis and L.g. guanicoe). Methods: We used maximum entropy to model lineage's climate niche from 3,321 locations throughout continental Chile, and developed future niche models under climate change for two extreme greenhouse gas emission scenarios (RCP2.6 and RCP8.5). We evaluated changes of the environmental niche and future distribution of the largest mammal in the Southern Cone of South America. Evaluation of niche conservatism and divergence were based on identity and background similarity tests.

Results: We show that: (a) the current geographic distribution of lineages is associated with different climatic requirements that are related to the geographic areas where these lineages are located; (b) future distribution models predict a decrease in the distribution surface under both scenarios; (c) a 3\% decrease of areal protection is expected if the current distribution of protected areas is maintained, and this is expected to occur at the expense of a large reduction of high quality habitats under the best scenario; (d) current and future distribution ranges of guanaco mostly adhere to phylogenetic niche divergence hypotheses between lineages.

Discussion: Associating environmental variables with species ecological niche seems to be an important aspect of unveiling the particularities of, both evolutionary patterns and ecological features that species face in a changing environment. We report specific descriptions of how these patterns may play out under the most extreme climate change predictions and provide a grim outlook of the future potential distribution of guanaco in Chile. From an ecological perspective, while a slightly smaller distribution area is expected, this may come with an important reduction of available quality habitats. From the evolutionary perspective, we describe the limitations of this taxon as it experiences forces imposed by climate change dynamics. 
Subjects Biogeography, Conservation Biology, Evolutionary Studies, Taxonomy, Climate Change Biology

Keywords Environmental niche modeling, Climate change, Ungulate conservation, MaxEnt

\section{INTRODUCTION}

Human induced climate change is imposing severe challenges to the equilibrium of natural ecosystem functioning (IPCC, 2013). Organisms will either have to face extinctions or adapt (Berg et al., 2010) by altering their seasonal activities, home ranges, migratory patterns, abundances, and interspecific interactions (Lenoir et al., 2008; Araújo, Thuiller \& Yoccoz, 2009; Elith \& Leathwick, 2009; Pecl et al., 2017). The global rise of temperatures will likely accelerate extinction risks and threaten up to one in every six species (Urban, 2010). Studies on the impact of climate change on ungulates have shown that changes in distribution ranges include altitudinal shifts in mountain environments (Mason et al., 2014) and distributional shifts towards equivalent habitats ( $\mathrm{Hu} \&$ Jiang, 2011). In more extreme cases, local extinctions will be driven by environmental aridization (Thuiller et al., 2006; Duncan et al., 2012).

In Chile, current projections of greenhouse gas (GHG) emissions proposed by the Intergovernmental Panel on Climate Change (IPCC) indicate that temperature will increase in a North to South gradient (IPCC, 2013). A large $2.5^{\circ} \mathrm{C}$ increase is expected in the Altiplano under the most extreme emission scenario and a milder $0.5^{\circ} \mathrm{C}$ increase is projected in the southern region of Magallanes for the period 2031-2050. Additionally, a $10-15 \%$ decrease in precipitation is expected in the middle of the country (between 25 and $45^{\circ} \mathrm{S}$ ), while forecasting a $5 \%$ rainfall increase in Patagonia and a similar snowfall decrease in the Magallanes region (Rojas, 2012).

The guanaco (Lama guanicoe) is both the most abundant native ungulate and the largest $(120 \mathrm{~kg}$ ) artiodactyl in South America (Franklin, 1982). The species is widely distributed throughout the Southern Cone, inhabiting cold, arid, and semiarid environments from sea level up to 5,000 m a.s.l. extending from northwestern Peru to Tierra del Fuego and Isla Navarino in the southern tip of the continent, with small populations roaming east of the Andes in the arid Chaco of Bolivia and Paraguay (Franklin, 1982; González et al., 2006). The highest population densities are found in the Andes and in Patagonia (Baldi et al., 2016). The species is characterized by specific anatomical, physiological, and reproductive adaptations to thrive and survive in arid environments despite the intense competition with livestock and severe degradation of their habitat (González et al., 2013; Marin et al., 2013; Baldi et al., 2016). The guanaco has a defined ecological role in each of its ecoregions either controling vegetation growth or dispersing seeds (González et al., 2006). These characteristics make the guanaco an important element within the tropic chain. For instance, it is the main prey of the puma (Puma concolor) (Franklin et al., 1999) and is the target of scavengers such as the chilla fox (Lycalopex griseus), the culpeo fox (Lycalopex culpaeus), and the Andean condor (Vultur gryphus) among others (Travaini et al., 2001; González et al., 2006). 
Two distinct subspecies of guanaco (L.g. cacsilensis and L.g. guanicoe) have been proposed based on genetic studies. L.g. cacsilensis is distributed to the west of the Central Andean Plateau throughout Peru and the northern tip of Chile with occurrences mostly explained by elevation and precipitation seasonality. L.g. guanicoe is found on the southeastern slope of the Andes, ranging throughout Patagonia and Tierra del Fuego with occurrences mostly explained by annual precipitation, precipitation seasonality and grass cover (González et al., 2013; Marin et al., 2013, 2017). The geographical limit between the northwestern and southeastern lineages has been proposed to occur around $31^{\circ} \mathrm{S}$ in Chile (Marin et al., 2017) and the significant genetic structure found among the two guilds has led to recommend to classify the two lineages as evolutionary significant units (ESUs) following Moritz's (1994) criteria (González et al., 2013; Marin et al., 2013). However, the two lineages are not completely separated from each other. In fact, some populations have individuals of both lineages forming zones of mixed genetic heritage (Marin et al., 2013). The distribution of this mixed population is predicted to occur at the south end of the Altiplano, between $26^{\circ}$ and $32^{\circ} \mathrm{S}$ approximately, and it is better explained by annual precipitation and precipitation seasonality (González et al., 2013). As reported by Marin et al. (2013), the Andean plateau could have acted as a biogeographical and ecological barrier fostering vicariance processes that may be at the origin of the current distribution of guanaco lineages. It is presumed that climate changes that occurred in the past allowed the establishment of populations over this geographic barrier, with periods of connectivity and isolation allowing the establishment of populations with mixed genetic heritage (Marin et al., 2013).

While the discontinuity of the current geographical distribution of guanaco is mostly a consequence of recent human activities (González et al., 2006), the macroevolutionary processes leading to lineage divergence in guanaco should be taken into consideration when deciding on the conservation actions required, as it has been discussed elsewhere for other species ( Hu et al., 2015). Current threats are mostly related to high competition for fodder with cattle and introduced mammals (Mason et al., 2014); predation by feral dogs, illegal hunting, and the reduction of available habitat due to the intensification of agriculture (González et al., 2006; Baldi et al., 2016). The 14.5 million hectares protected by the Chilean system of protected areas (PA) does not cover the entire species range (Baldi et al., 2016), prompting important questions regarding the future distribution of guanaco. Mostly, L. guanicoe is well adapted to a wide variety of habitats (González et al., 2006, 2013). However, at the intraspecific level, each lineage may respond differently to changes. As evidence from guanaco's natural history indicates, past changes in climate have clearly influenced the geographic distribution of this species, particularly in the Altiplano and Puna where guanacos and vicuñas (Vicugna vicugna) compete for resources since the Holocene (Marin et al., 2013, 2017). Thus, under the possible climate change scenarios in Chile, we expect L.g. cacsilensis to expand (or to shift) southward and overlap with the mixed genetic heritage population. On the other hand, we predict that L.g. guanicoe, characterized by a wider climatic tolerance (González et al., 2013), should mostly maintain its current geographic distribution. 
From an evolutionary perspective, given the existence of these two lineages and the repeated suggestions of their consideration as ESUs (Marin et al., 2013; Baldi et al., 2016), it would be of great interest to evaluate the state of conservation of their niche to support with new evidence this classification. From such perspective, it becomes relevant to assess whether phylogenetic niche conservatism (PNC), the tendency of closely related species to differ less ecologically than expected by chance, or otherwise, phylogenetic niche divergence (PND), the tendency of closely related species to differ more ecologically than expected by chance may prevail under current and predicted niche segregation patterns under future climate change (Pyron et al., 2015; Meynard et al., 2017).

Based on the latest projections of climate change in the region (Rojas, 2012; IPCC, 2013) and the understanding of L. guanicoe taxonomy and life history, we developed models based on niche theory to assess the impact of climate change on guanaco's ESUs. By modeling the niche of L. guanicoe and its lineages we here: (a) estimated their current geographic distribution based on bioclimatic variables; (b) predicted their future distribution based on the projections of the best and worst climate change scenario at two different time frames (2050, 2070); (c) quantified the area predicted to be gained, lost, or remain stable in the future for both guanacos lineages and mixed population; (d) evaluated and compared how much of the Chilean PA will overlap with the future distribution area calculated for guanacos; and (e) explored the existence of niche conservatism or divergence between L. guanicoe lineages, in terms of their niche equivalence (Graham et al., 2004) and similarity (Peterson, Soberón \& Sánchez-Cordero, 1999).

\section{METHODS}

\section{Species occurrence data}

We built a guanaco occurrence dataset of 3,321 records by complementing previous work by the authors with 359 additional records (González et al., 2013). New records were collected following the same procedures outlined in González et al. (2013), that is, from direct and indirect evidence of guanaco presence collected between the years 2000 and 2016 across several field campaigns. Indirect evidence of guanaco occurrence was assigned to a lineage by genetic and morphological evaluation of biological samples such as feces and dead tissues. Most of new records were collected in the northern section of the country in the Arica, Parinacota (i.e., $17^{\circ} \mathrm{S}$ latitude) and Coquimbo region (30 $\mathrm{S}$ ). Each record was assigned to a $1 \times 1 \mathrm{~km}$ cell defined by the resolution of the environmental datasets employed (see below). This resulted in a total of 298 records for L.g. cacsilensis, 837 for the mixed population, and 2,186 for L.g. guanicoe.

\section{Climate predictors}

We limited the selection of environmental predictors to climatic variables (Thuiller et al., 2006; Hu et al., 2015). Similarly to what has been described in the literature (Thuiller et al., 2004), our previous work dismissed the importance of nonclimate predictors for guanaco distribution models in favor of exclusive climatic variables (González et al., 2013). We used all 19 bioclimatic variables from WorldClim (version 1.4) summarizing temperature and precipitation information worldwide (Hijmans et al., 2005). To reduce 
collinearity, model overfitting, and the number of explanatory variables, we used a paired correlation analysis to inspect pairs of variables and removed variables with a large correlation coefficient (>0.8) (Beaumont, Hughes \& Poulsen, 2005).

While the analysis was limited to the administrative bounds of Chile, all WorldClim variables were projected to UTM 19 South, with a one squared-kilometer of spatial resolution, spanning from latitudes $15^{\circ}$ to $55^{\circ} \mathrm{S}$ and longitudes $60^{\circ}$ to $80^{\circ} \mathrm{W}$ and a total area of 5,921,578 $\mathrm{km}^{2}$ covering most of the Southern Cone.

\section{Future Climate Projections}

The projection of future geographic distribution of niches was performed using the outputs of the Coupled Model Intercomparison Project 5 of the IPCC's methodology for the Fifth Assessment Report (AR5) (Taylor, Stouffer \& Meehl, 2012). The two extreme GHG concentration scenarios, also known as representative concentration pathway (RCP), were used to project future climate niches. RCP2.6, the most optimistic scenario, considers a lower GHG concentration and projects average increases of temperature between $0.3^{\circ}$ and $1.6^{\circ} \mathrm{C}$ with $0.26-0.55 \mathrm{~m}$ increases of sea levels. RCP8.5, the most pessimistic scenario, considers higher GHG concentrations with a $2.6^{\circ}-4.8^{\circ} \mathrm{C}$ projected increase in mean global temperature and a $0.45-0.82 \mathrm{~m}$ rise of sea levels (IPCC, 2013). We chose both extreme scenarios to evaluate the minimum and maximum potential impact of climate change in the guanaco's distribution.

Given the large uncertainties of future climate predictions, the computing power availability and the exploratory nature of such models, we selected five general circulation models (GCM) among the 19 models used to generate the AR5. GCM's are physical climate models that simulate the interactive biophysical processes between the atmosphere, the ocean and the land (Moss et al., 2010). Selected climate models were: (1) CCSM4 model of the National Center of Atmospheric Research (Gent et al., 2011); (2) GFDL-CM3 model of the Geophysical Fluid Dynamics Laboratory (Donner et al., 2011); (3) GISS-E2-R model of the NASA Goddard Institute for Space Studies (Nazarenko et al., 2015); (4) HadGEM2-AO atmosphere model and (5) HadGEM2-ES earth system model, both of the Met Office Hadley Centre (Collins et al., 2011). Each scenario was evaluated for the short (2050) and medium term (2070).

\section{Niche modeling}

Entropy maximization procedures in MaxEnt 3.3.3 k (Phillips, Anderson \& Schapire, 2006) were used to model current and future geographic distributions of L. guanicoe and its lineages. MaxEnt uses a machine learning algorithm to generate predictions on the potential distribution of species based on their presence, pseudo-absences and a set of environmental variables. The software analyzes the multivariate distribution of environmental conditions of species occurrences to generate a spatially explicit probability map of lineage occurrence (Franklin, 2009). Such modeling approach has shown to have a good statistical performance compared to other types of modeling techniques (Elith et al., 2006) and is currently one of the most commonly used methods to understand habitat suitability, 
niche structure, geographical species distribution (Merow, Smith \& Silander, 2013) as well as to project environmental niches to future scenarios (Hijmans \& Graham, 2006).

We performed 100 cross-validated replicates for each current and projected distribution model with logistic output, that unlike other outputs (i.e., raw and cumulative) assumes that a known observation probability can be assigned to each pixel and has thus been considered as a true approximation of presence (Merow, Smith \& Silander, 2013). The "fade by clamping" option was used to avoid predictions beyond the observed geographical range during the training of the future distributions models (Phillips, Anderson \& Schapire, 2006). All other parameters were kept at their default configuration (Phillips, Dudik \& Schapire, 2004) as they have previously shown good performance in ungulate modeling ( Hu \& Jiang, 2011; González et al., 2013; Hu et al., 2015; Quevedo et al., 2016) and other taxonomic groups (Phillips \& Dudik, 2008; Fourcade et al., 2014).

We used an ensemble forecasting framework to minimize the inherent variability introduced by the various forecast models employed, as proposed by Araújo \& New (2007). Therefore, we generated a model from the average of each bioclimatic variable produced by the five GCMs (i.e., $B i o 1_{\mathrm{CC}}+\mathrm{Biol}_{\mathrm{GF}} \mathrm{Bio} 1_{\mathrm{GS}}+\mathrm{Bio}_{\mathrm{HD}}+\mathrm{Bio}_{\mathrm{HE}}$ ), and then evaluated an average value for each variable from 100 replicates for both extreme RCP emission scenarios for the years 2050 and 2070 . Hence, 400 projected guanaco distribution models were generated (i.e., 2 RCPs $\times 2$ time frames $\times 100$ replicates). The final results are four projected climate models for L. guanicoe, one for each RCP2.6 and RCP8.5 scenarios evaluated for years 2050 and 2070.

\section{Model evaluation, prediction, and spatial projection}

Generated niche models were evaluated using a threshold-independent analysis of the area under the curve (AUC) provided by the receiver operator curve (Phillips, Anderson \& Schapire, 2006; Acevedo et al., 2010; Anderson \& Raza, 2010). These sensitivity tests model accuracy by calculating the proportion of true positives versus false positives. The resulting values range from 0 to 1 , where model predictions are considered fair when obtained AUC values are above 0.7 (Swets, 1988; Merow, Smith \& Silander, 2013). A 3:1 ratio was used to divide training and testing datasets (Phillips, Anderson \& Schapire, 2006). AUC Jackknife analysis allowed to identify the contribution of each variable to final current and future models, and to allow the detection of those variables that significantly improve predictions for the occurrences of each lineage (Phillips, Anderson \& Schapire, 2006).

We reclassified predicted habitat using a 0.25 threshold interval to label three habitat suitability classes: low suitability habitat when occurrence probability ranged between $25 \%$ and $50 \%$; suitable habitat if occurrence probability was in the $50-75 \%$ interval; and high suitability habitat if occurrence probability was over $75 \%$, values below $25 \%$ were considered as inappropriate habitat (Hu \& Jiang, 2012; González et al., 2013; Shrestha \& Bawa, 2014).

\section{Changes in distribution surface and incidence in protected areas}

The areal extent for each suitability class predicted by each model, current and projected, were compared to determine habitat loss (or gains) under the various climate change 
scenarios evaluated. We used the software BioSARN v. 1 to calculate the amount of area gained or lost and to estimate differences between models (Heap, 2016). These results were classified into three categories: (a) Areal loss, when future prediction show a decrease of the areal extension compared to current niche models; (b) Areal gain, produced when future prediction add area to current niche models; (c) Unchanged areas, when climate change predictions show no impact on current guanaco's distribution.

In addition, the fraction of future distribution covered by the system of PA in Chile was estimated. All categories offering some level of protection were considered: national parks, national reserves, biosphere parks, national monuments, national patrimony, and private PA as of 2011. RAMSAR sites (as of 2012) were also included as they constitute the most important feeding grounds for guanaco in the hyper-arid north of Chile (Squeo et al., 2006).

\section{Evaluation of PNC or PND}

Phylogenetic niche conservatism and phylogenetic niche divergence among lineages and the mixed population were evaluated through their current and projected niches for the most extreme scenario (i.e., RCP8.5) in 2070 using ENMTools v.1.4.3 (Warren, Glor \& Turelli, 2010). Niche overlap between lineages was calculated with the statistical indices " $P$ ” (derivative of Hellinger's distance) and " $D$ ” (Shöener's D) which may take values going from 0 (i.e., no overlap) to 1 (i.e., full overlap between lineages' niches). We used the Identity test to evaluate the hypothesis of niche equivalence (Graham et al., 2004) and the Background similarity test to evaluate the hypothesis of niche similarity (Peterson, Soberón \& Sánchez-Cordero, 1999). The Identity test quantitatively assesses whether the niche space for two compared lineages are equivalent by comparing the actual niche to a null niche model generated from a randomized pool of locations for each lineage. This allows to effectively evaluate whether niche spaces are equal, under the premise that, if they are, they should be able to predict each other (Warren, Glor \& Turelli, 2010). Because the Identity test strongly depends on accurate representations of species habitat suitability, it is known to be sensitive to the particular sampling scheme employed, and therefore less suitable to compare allopatric niches (Warren, Glor \& Turelli, 2010). The Background similarity test compares the niche difference between allopatric lineages by contrasting the niche of a "focal" lineage to the niche built from the background locations of a second lineage. If there is similarity between these, the null model should predict the niche of the second lineage. We repeated each test 100 times to produce a simulated distribution of $I$ and $D$ values and to evaluate significance using a threshold of 0.1 (two-tailed for background similarity test, and onetail for identity test) (Warren, Glor \& Turelli, 2010; Guisan, Thuiller \& Zimmermann, 2017). We considered outcomes as indicative of PNC between lineages when observed $I$ and $D$ values fell within the simulated distribution. On the other hand, when the observed values fell outside of the simulated distribution, they were assumed to be indicative of PND between lineages. 


\section{RESULTS}

\section{Selection of climate variables and current distribution model}

After removing correlated variables, the final subset of independent bioclimatic variables used in this analysis was composed of: annual mean temperature (Bio1), temperature seasonality (Bio4), annual temperature range (Bio7), annual precipitation (Bio12), and precipitation seasonality (Bio15). See correlation analysis in supplemental Fig. S1.

The major contribution to the current distribution of L. guanicoe was given by the annual range of temperature $(28.2 \%, \mathrm{AUC}=0.84)$, whereas L.g. cacsilensis was dominated by precipitation seasonality $(66.7 \%$, AUC $=0.95)$, the mixed population by annual precipitation $(36.7 \%, \mathrm{AUC}=0.93)$, and the southernmost L.g. guanicoe was mostly driven by annual mean temperature $(35.8 \%$, AUC $=0.91)$. Detailed Jackknife's analysis can be seen in supplemental information, Fig. S2.

All current distribution models generated for L. guanicoe and its lineages, presented a good performance with mean AUC values over 0.89. The resulting geographic range for guanaco spanned for about a third of the Chilean continental surface. The geographic areas covered by L.g. cacsilensis and L.g. guanicoe were of 47,148 and 100,539 km², respectively. The mixed population showed a geographic extent of $84,976 \mathrm{~km}^{2}$. Interestingly, our models had a $20 \%$ difference when comparing areas from the sum of lineages modeled independently and the total area modeled with all the lineages pooled as if they were a single lineage (232,664 vs. $284,499 \mathrm{~km}^{2}$, respectively). Full maps and predictions are available in supplemental information Fig. S3.

\section{Projected distribution models}

As for current distribution models, the sensitivity analysis yielded a large mean AUC >0.9. After suitability categorization (Fig. 1), our results show that while the geographical distribution pattern of guanaco is conserved, quantitative assessment of the distribution surface reveals a downward trend in both scenarios of climate change for 2050 and 2070 (Table 1).

Marginal decreases of habitat suitability is observed under the RCP2.6 scenario for the years 2050 and 2070 (259,577 vs. $254,979 \mathrm{~km}^{2}$, respectively). The small areal reduction under both models is only of $6 \%$ and $7.6 \%$ of the current area. However, this decrease is more pronounced under the RCP8.5 scenarios in which a $13 \%$ and $20.7 \%$ reduction is quantified for the years 2050 and 2070, respectively (i.e., 240,505 and $\left.218,841 \mathrm{~km}^{2}\right)$.

\section{Surface change between current and projected distribution models}

Projected distribution models under the more optimistic scenario showed an increase of high quality habitat and a net loss of medium and low quality habitat, while the projections under the worst scenario indicate a generalized decrease in habitat suitability. Although no important loss of potential distribution areas are apparent, a large decrease 


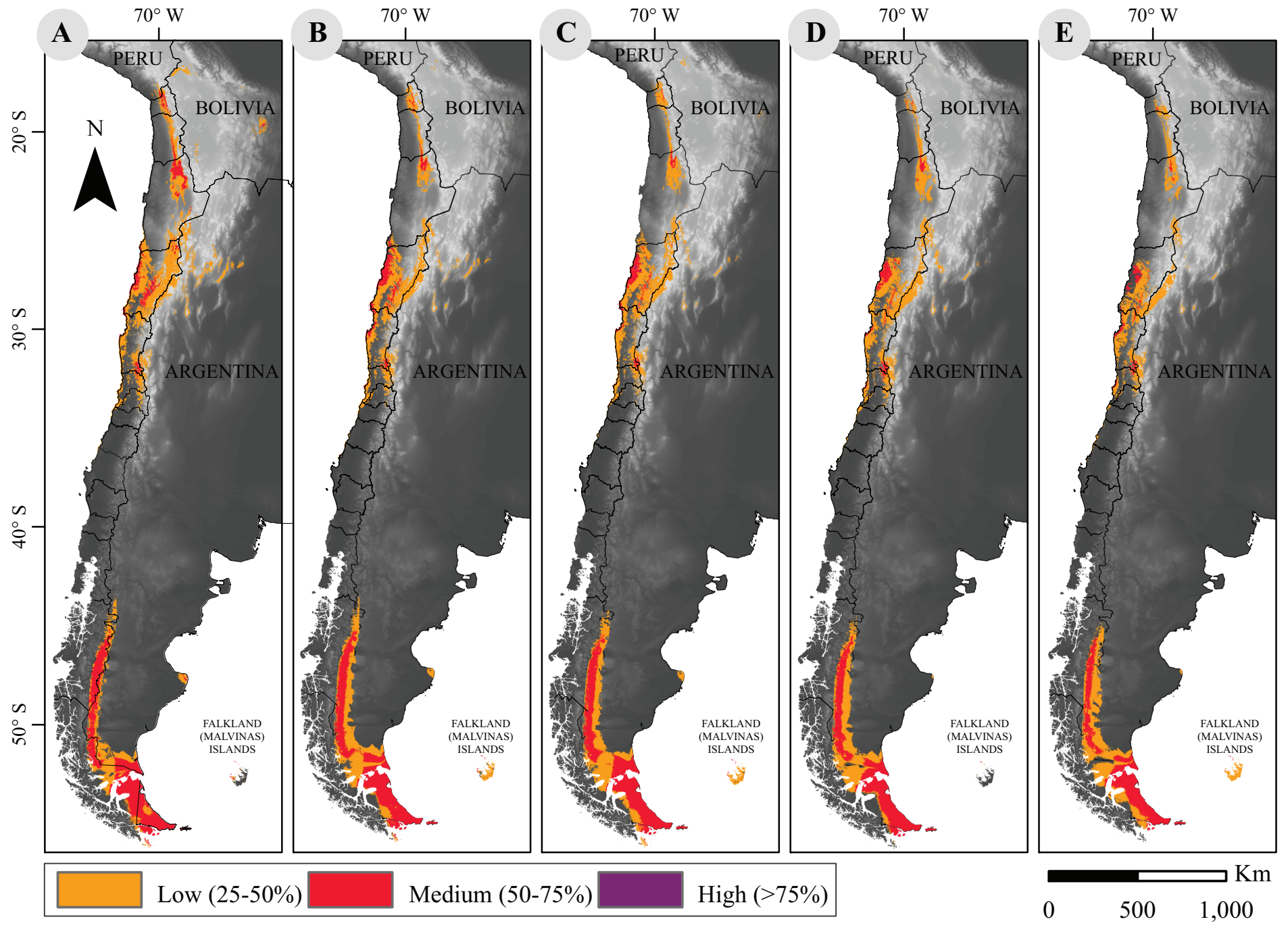

Figure 1 Current and projected distribution model of guanaco lineages in South America. (A) Current distribution; and projected distributions (B) under RCP2.6 to 2050; (C) under RCP2.6 to 2070; (D) under RCP8.5 to 2050; (E) under RCP8.5 to 2070. These surfaces were classified according to habitat suitability. Base Map Elevation Data: CIAT-CSI SRTM (http://srtm.csi.cgiar.org).

Full-size $\emptyset$ DOI: $10.7717 /$ peerj.4907/fig-1

of areas with high quality habitat may occur under the worst climate change scenario evaluated (Table 1).

Surface losses and gains under future climate projections are described in Table 2. Both scenarios showed that a large fraction of the guanaco range will remain unchanged. The more optimistic projection (i.e., RCP2.6) indicated an average loss of 67,042 $\mathrm{km}^{2}$ between 2050 and 2070, and a niche displacement (i.e., gain) of $48,225 \mathrm{~km}^{2}$ on average between such time periods. A reversed trend was observed under the more pessimistic scenario (i.e., RCP8.5) with the larger change predicted for 2070. Such prediction forecasts a reduction in guanaco's niche by $37 \%$, with a surface loss of $103,367 \mathrm{~km}^{2}$ and a geographic distribution of $172,786 \mathrm{~km}^{2}$. Likewise, the smallest niche displacement was observed for this period, with $46,089 \mathrm{~km}^{2}$ of areal gain (Fig. 2). 
Table 1 Geographic distribution area $\left(\mathrm{km}^{2}\right)$ of current potential distribution of L. guanicoe across habitat suitability categories.

RCP2.6

\begin{tabular}{llllll}
\hline Suitability category & Current (Fig. 1A) & 2050 (Fig. 1B) & 2070 (Fig. 1C) & 2050 (Fig. 1D) & 2070 (Fig. 1E) \\
High $(>75 \%)$ & 23 & 71 & 258 & 3 & 0 \\
Medium (50-75\%) & 102,693 & 94,574 & 88,295 & 80,653 & 66,344 \\
Low $(25-50 \%)$ & 173,353 & 164,932 & 166,427 & 159,849 & 152,497 \\
Total & 276,069 & 259,577 & 254,979 & 240,505 & 218,841 \\
\hline
\end{tabular}

Notes:

Environmental niche models are projected to years 2050 and 2070 under the most extreme greenhouse gas emission scenarios. RCP2.6 represents climate model under the less severe emission scenario and RCP8.5 the scenario under the largest greenhouse gas emission.

Table 2 Percent change of distribution area between current and projected models for 2050 and 2070 under the most extreme climate change projections.

\begin{tabular}{lllll}
\multicolumn{4}{c}{ RCP2.6 } & \multicolumn{1}{l}{ RCP8.5 } \\
\hline & 2050 (Fig. 2A) & 2070 (Fig. 2B) & 2050 (Fig. 2C) & 2070 (Fig. 2D) \\
Losses $\left(\mathrm{km}^{2}\right)$ & $66,634(24 \%)$ & $67,450(24 \%)$ & $86,540(31 \%)$ & $103,367(37 \%)$ \\
Unchanged $\left(\mathrm{km}^{2}\right)$ & $209,519(76 \%)$ & $208,703(76 \%)$ & $189,613(69 \%)$ & $172,786(63 \%)$ \\
Gains $\left(\mathrm{km}^{2}\right)$ & $50,106(18 \%)$ & $46,343(17 \%)$ & $50,968(18 \%)$ & $46,089(17 \%)$ \\
\hline $\begin{array}{l}\text { Notes: } \\
\text { Areal losses, unchanged and gains in square kilometers for each RCP model with respect to current potential } \\
\text { distribution of guanaco. Percentage changes are shown in parentheses. }\end{array}$
\end{tabular}

\section{Evaluation of PNC and PND}

Niche overlap and equivalence tests showed a large overlap between the contact population and L.g. cacsilensis for niche models under current and worst scenarios (Table 3). While limited niche overlap was reported, the overlap between the northern lineage and the mixed population increased under future climate change scenarios. On the other hand, the overlap between current and projected niches for L.g. guanicoe with the other groups was smaller, particularly with the northern lineage (L.g. cacsilensis). When using the results of this latter analysis as "empirical values" to perform identity and background similarity tests (Tables 3 and 4), we were able to show that statistical differences existed when comparing current niches and projected niches. This indicates that the climatic requirements between the lineages and mixed population are not equivalent.

Background similarity test showed that L.g. cacsilensis share climatic similarities with the mixed population (Table 4). However, such similarity is not reciprocal when comparing the climatic requirements of the mixed population to those of the northern lineage-a possibility mentioned in Warren, Glor \& Turelli (2010). A similar situation occurred when comparing projected niches under the worst climate change scenario (RCP8.5), where results suggested that L.g. guanicoe's niche will closely resemble the future climatic niche of the mixed population, in spite of not sharing any current similarity. 


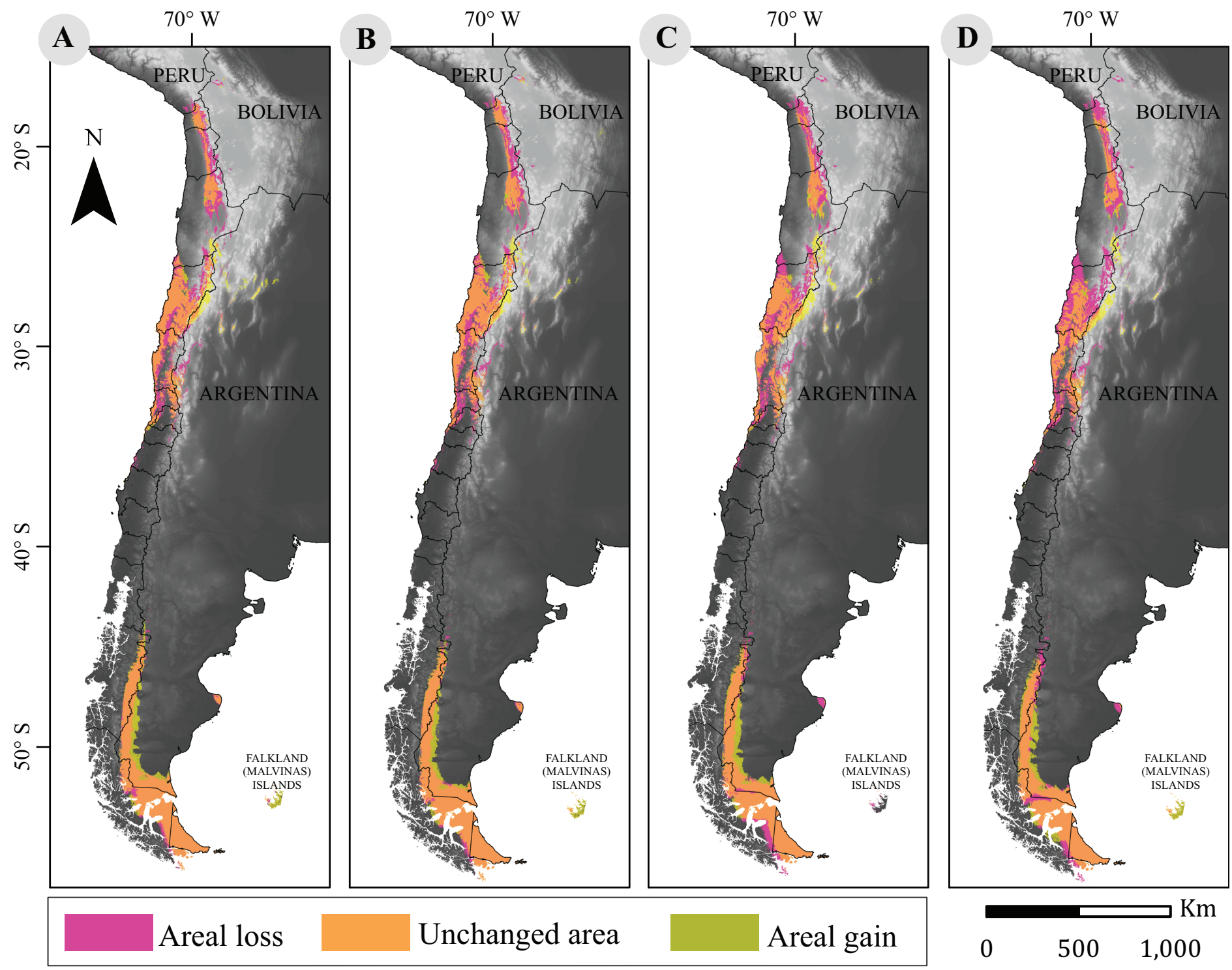

Figure 2 Cartographic projection of changes in distribution. Pink surface corresponds to areal loss and representing the areal fraction of the climatic niche that exists only in the current model. Olive surface corresponds to areal gains and represents the climatic niche area that exists only in the projected model. Orange surface corresponds to the area that has remained unchanged and represents the surface of the climatic niche that exists in both models (current and projected models). Panel (A) is the comparison between current and projected model under RCP2.6 to 2050; (B) the comparison between current and projected model under RCP2.6 to 2070; (C) the Comparison between current and projected model under RCP8.5 to 2050; (D) is the comparison between current and projected model under RCP8.5 to 2070. Base Map Elevation Data: CIAT-CSI SRTM (http://srtm.csi.cgiar.org). Full-size iص DOI: 10.7717/peerj.4907/fig-2

The remaining comparisons between climatic niches, current and future, showed that the climatic requirements for each of the lineages analyzed are significantly different (Table 4).

\section{Projected distribution models and conservation in Chile}

The current network of PA in Chile covers a vast area of approximately $256,550 \mathrm{~km}^{2}$, according to 2016 data, and shows a limited overlap with modeled guanaco distribution. 
Table 3 Niche identity test.

\begin{tabular}{|c|c|c|c|c|c|}
\hline \multirow[t]{2}{*}{ Niche model } & \multirow[t]{2}{*}{ Compared lineages } & \multicolumn{2}{|c|}{ Empirical value (Niche overlap) } & \multicolumn{2}{|c|}{ Identity test (Niche equivalence) } \\
\hline & & $I$ & $D$ & $I$ & $D$ \\
\hline \multirow[t]{3}{*}{ Current } & L. g. cacsilensis-Mixed population & 0.283 & 0.089 & 0.923 & 0.686 \\
\hline & L. g. guanicoe-Mixed population & 0.178 & 0.058 & 0.922 & 0.711 \\
\hline & L. g. cacsilensis-L. g. guanicoe & 0.133 & 0.033 & 0.922 & 0.596 \\
\hline \multirow[t]{3}{*}{ Projected (2070) } & L. g. cacsilensis-Mixed population & 0.471 & 0.208 & 0.930 & 0.760 \\
\hline & L. g. guanicoe-Mixed population & 0.135 & 0.039 & 0.950 & 0.800 \\
\hline & L. g. cacsilensis-L. g. guanicoe & 0.090 & 0.015 & 0.890 & 0.630 \\
\hline
\end{tabular}

Notes:

These results correspond to the comparison between the empirical values (niche overlap) and values of percentiles 0.1 of the null distribution (one tailed, Warren, Glor \& Turelli, 2010). The " $P$ " and " $D$ " statistics allow to compare the overlap between the replicas of this test. If the empirical value is within the range of values observed in the percentages, the hypothesis of niche equivalence is supported (shown in bold type).

Table 4 Background similarity test.

\begin{tabular}{|c|c|c|c|c|c|c|c|c|}
\hline & \multicolumn{2}{|l|}{ Compared lineages } & \multicolumn{2}{|c|}{ Niche overlap } & \multicolumn{4}{|c|}{ Background similarity test } \\
\hline \multicolumn{5}{|l|}{ Niche } & \multicolumn{2}{|c|}{$p=0.01$} & \multicolumn{2}{|c|}{$p=0.90$} \\
\hline Model & Focal & Background & $D$ & $I$ & $D$ & $I$ & $D$ & $I$ \\
\hline \multirow[t]{6}{*}{ Current } & L. g. cacsilensis & Mixed population & 0.089 & 0.283 & 0.082 & 0.260 & 0.115 & 0.320 \\
\hline & Mixed population & L. g. cacsilensis & 0.089 & 0.283 & 0.094 & 0.304 & 0.108 & 0.336 \\
\hline & L. g. guanicoe & Mixed population & 0.058 & 0.133 & 0.136 & 0.358 & 0.140 & 0.366 \\
\hline & Mixed population & L.g. guanicoe & 0.058 & 0.133 & 0.091 & 0.302 & 0.107 & 0.332 \\
\hline & L. g. cacsilensis & L. g. guanicoe & 0.033 & 0.178 & 0.091 & 0.273 & 0.124 & 0.332 \\
\hline & L. g. guanicoe & L. g. cacsilensis & 0.033 & 0.178 & 0.136 & 0.359 & 0.141 & 0.368 \\
\hline \multirow[t]{6}{*}{ Projected (2070) } & L. g. cacsilensis & Mixed population & 0.208 & 0.471 & 0.158 & 0.387 & 0.169 & 0.410 \\
\hline & Mixed population & L. g. cacsilensis & 0.208 & 0.471 & 0.055 & 0.211 & 0.074 & 0.251 \\
\hline & L. g. guanicoe & Mixed population & 0.039 & 0.135 & 0.033 & 0.123 & 0.042 & 0.148 \\
\hline & Mixed population & L. g. guanicoe & 0.039 & 0.135 & 0.011 & 0.055 & 0.016 & 0.072 \\
\hline & L. g. cacsilensis & L. g. guanicoe & 0.015 & 0.090 & 0.006 & 0.042 & 0.010 & 0.058 \\
\hline & L. g. guanicoe & L. g. cacsilensis & 0.015 & 0.090 & 0.018 & 0.080 & 0.020 & 0.085 \\
\hline
\end{tabular}

Notes:

The first column indicates whether the analysis was applied on current or projected niche models. Second and third columns indicate compared lineages and focal lineage used for the comparison. These results show the comparison between the empirical values (niche overlap results) and 0.1 and 0.9 percentiles of the null distribution (two tailed, Warren, Glor \& Turelli, 2010) delivered by the test. If the empirical value is within the range of values observed in the percentages, the hypothesis of niche similarity is supported (shown in bold type).

In fact, our analysis shows that a $9.8 \%$ (i.e., $19,402 \mathrm{~km}^{2}$ ) of the species current distribution overlaps with a PA. When looking at projected distributions for 2070, our results showed that such overlap will decrease to $6.2 \%\left(15,772 \mathrm{~km}^{2}\right)$ under the best scenario (RCP2.6). Similarly, under the worst scenario (RCP8.5), the overlap will be of $5.7 \%\left(12,434 \mathrm{~km}^{2}\right)$ (Fig. 3).

\section{DISCUSSION}

Understanding species' response to climate change is crucial in order to adequately manage conservation efforts (Thomas et al., 2004; Araujo \& Rahbek, 2006; Warren et al., 2013). Several authors have already warned about the dire consequences of climate change on 

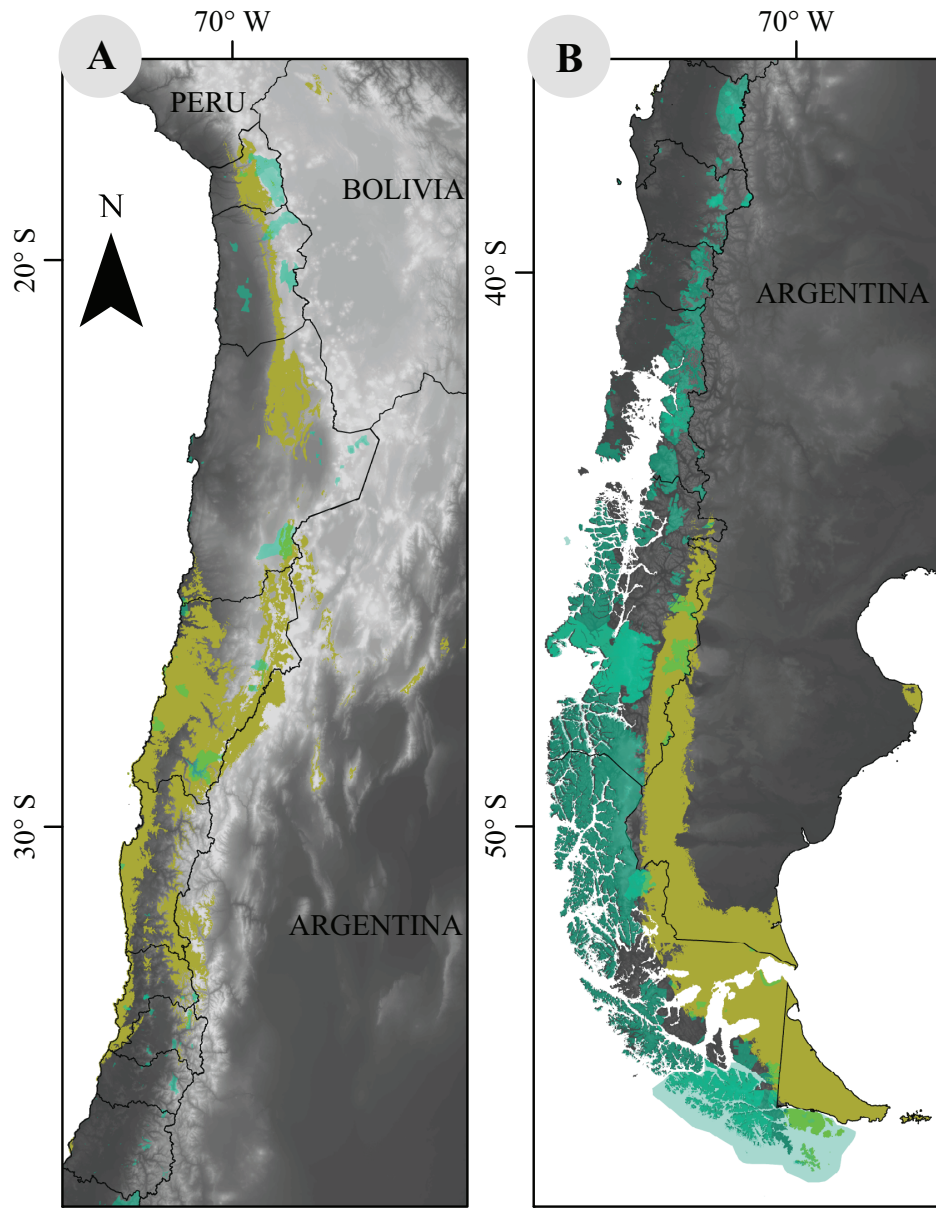

Projected distribution

Protected areas

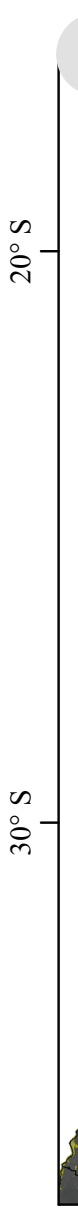

C

$70^{\circ} \mathrm{W}$
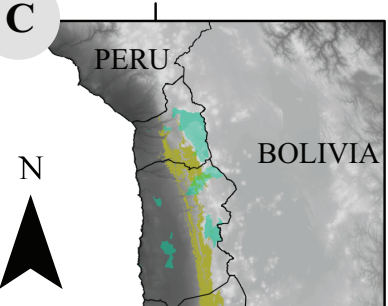

$\sum \mathrm{B}$

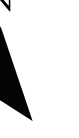

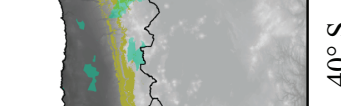

D

D

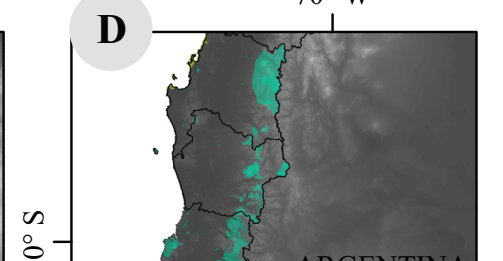

a
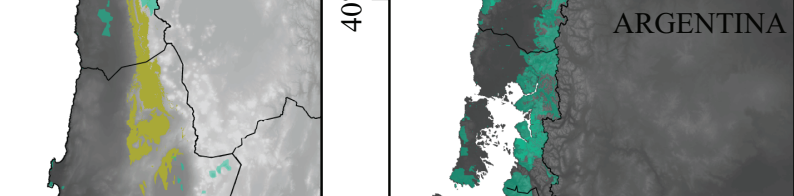

(

(3)

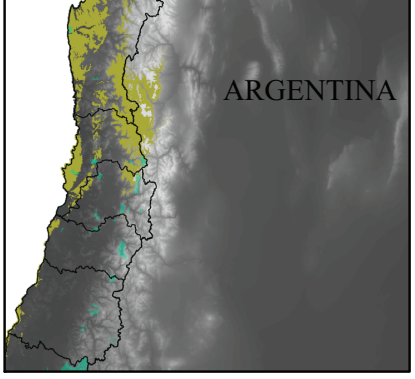

is

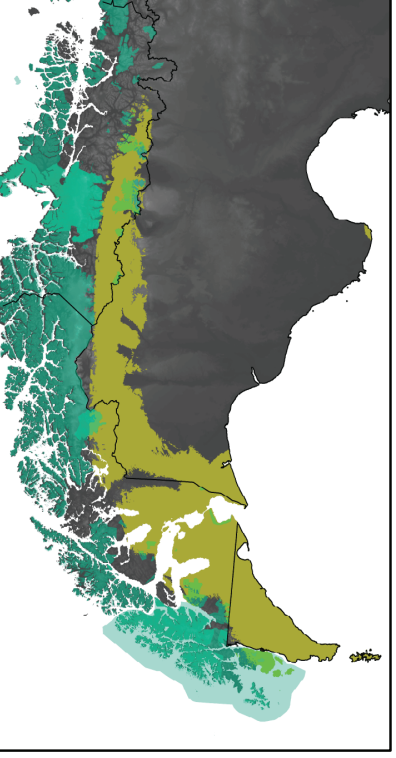

$\mathrm{Km}$

500

1,000

Figure 3 Overlap between projected environmental niche models under two extreme climate scenarios and distribution of protected areas in Chile. (A) and (B) are projections based on RCP2.6 scenarios; (C) and (D) correspond to RCP8.5 scenarios. Protected categories consider National Parks, National Reserves, Biosphere Reserves, National Monuments, Protected National Heritage, RAMSAR sites (2012), and Private Protected Areas (2011) (IDE, 2016). Base Map Elevation Data: CIAT-CSI SRTM (http://srtm.csi.cgiar.org). Full-size D DOI: 10.7717/peerj.4907/fig-3

ecosystems and across a wide range of taxa (Walther et al., 2002; Quintero \& Wiens, 2013; Muñoz-Mendoza et al., 2017). Our worst-case scenario analysis suggests that the guanaco will have lost up to a fifth ( 21\%) of its current geographic distribution by 2070. Although predicted changes will barely be noticeable, the classification and quantification of suitable habitat provided substantial insights on the vulnerability of this species to climate change showing that such changes will additionally result in a confinement to suboptimal quality habitats supporting general trends outlined in the literature (Urban, 2010; Pecl et al., 2017). In particular, our quantification of areal changes between current and future distribution under the worst-case scenario, suggested an average loss of $34 \%$, compared to $17 \%$ of areal gains (i.e., new distribution areas available) between 2050 and 2070 . 
Our analysis strongly associated the northern lineage L.g. cacsilensis to precipitation seasonality and predicted a southward shift in the future distribution of guanaco. However, our model outputs essentially predicted an eastern distributional shift into areas of low suitability between the Arica and Parinacota $\left(18^{\circ} \mathrm{S}\right)$, and the Atacama regions $\left(27^{\circ} \mathrm{S}\right)$ (Fig. 1). Other authors have predicted similar changes in the distribution area of ungulates in arid and semiarid environments as, for example, the silver dik-dik (Madoqua piacentinii, a small antelope), in the southeastern coast of Somalia (Thuiller et al., 2006). In other cases, extinction risks have increased with the intensification of drought episodes, as it has been seen for the hartebeest (Alcelaphus buselaphus, an African antelope), and the waterbuck (Kobus ellipsiprymnus, a large sub-Saharan antelope) (Duncan et al., 2012).

In the case of the guanaco in Chile, future distribution modeled here not only shows a confinement to specific zones, such as coastal and central valleys in the Atacama region $\left(27^{\circ} \mathrm{S}\right)$, and coastal and Andes Mountains between Coquimbo $\left(29^{\circ} \mathrm{S}\right)$ and Valparaíso $\left(33^{\circ} \mathrm{S}\right)$ regions, but also a reduction of the distribution extent of the mixed population. This roughly coincides with a predicted $5-15 \%$ rainfall reduction for the next decades between the Copiapó River $\left(27^{\circ} \mathrm{S}\right)$ and the Aysén river basin $\left(47^{\circ} \mathrm{S}\right)$ (Rojas, 2012; Garreaud et al., 2017).

In order to better understand spatial dynamics of guanaco's populations across their distribution range, we seeked to address whether niche conservatism or divergence prevailed under different climate change regimes. The basic assumption is that niches are diagnostic traits that help us understanding how species deal with climate-induced changes in their habitat (Wiens \& Graham, 2005; Alvarado-Serrano \& Knowles, 2014). For instance, sister lineages should most likely exhibit closely similar niches, and point towards PNC (Webb et al., 2002; Wiens \& Graham, 2005; Losos, 2008; Warren, Glor \& Turelli, 2008). Therefore, we expected to find niche similarity (i.e., PNC) between the niches of guanaco lineages. Nevertheless, we found stronger evidence for PND among L.g. cacsilensis and L.g. guanicoe, hence supporting the existence of only two ESUs for the guanaco, as proposed by Marin et al. (2013): one lineage in the northwest represented by L.g. cacsilensis and another in the southeast represented by L.g. guanicoe (see Tables 3 and 4). Two interesting results emerged when lineages' niches were compared with the mixed population: (i) the current niche of northern L.g. cacsilensis is similar to the current niche of the mixed population; (ii) the future niche of the southern L.g. guanicoe is projected to include, and resemble, the future niche of the mixed population.

Nevertheless, the current niche of the mixed population does not share any statistically significant similarity with the northern nor the southern lineages (see background similarity test results in Table 4). This suggests that L.g. cacsilensis is, given its actual climatic requirements, more likely to adapt to current climatic conditions across the mixed population's habitat, pointing towards the existence of PNC processes. Whereas when we look at projected climate conditions, L.g. guanicoe will most likely experience a future expansion of its environmental niche towards the projected mixed population's habitat. Conversely, the mixed population will continue to limit its distribution to the small and restricted areas of northern Chile, in spite of its recent dispersal history through extant barriers (Marin et al., 2013). In summary, PNC seems to be more important when 
current niches are analyzed, while PND emerges as the important process under future projections of climate change.

The high genetic variation observed for the guanaco lineage in Patagonia indicates that this area may have functioned as a climatic refuge for the species (Fuentes \& Jaksic, 1979; González et al., 2013). In order to safeguard the evolutionary potential of the species, conservation efforts should take into consideration the projected distributions of guanaco lineages (Pecl et al., 2017).

From our results, and under the best scenario, the current location of PA will only decrease a $3 \%$ of guanaco's protected distribution range, but will shift to lower quality habitat, as discussed above. Projected distributions models proposed in this study are by no means a prognosis of the fate of guanacos in Chile, as they outline the distribution probabilities based on possible scenarios given the future GHG emissions (IPCC, 2013). Furthermore, the limited geographic locations that fed our models and the uncertainties associated with GCMs (Buisson et al., 2010) have likely permeated our predictions (Moss et al., 2010). In fact, the net effect of our conservative forecasts may underestimate current and future species distribution both within the boundaries of Chile and beyond. For instance, the species may be influenced by a range of environmental conditions outside Chile that are currently not represented among the presence localities in Chile. Thus, when projecting the future distribution within Chile, these areas may appear as not environmentally suited for the presence of the species, altering the correct estimation for the area (or percentage) of range contraction and the area (or percentage) of the range in PA. Furthermore, addressing congruence between restricted and broad scale predictions, Titeux et al. (2017) suggested that local models might omit the warmest and coldest parts of future distribution, projecting a larger decrease in future species richness at warmer temperatures. Therefore, the validity of the proposed distribution of guanaco's future range in Chile likely depends on the consistency between the environmental niche used and the values present elsewhere, as well as on the extension of guanaco's presence in extreme temperatures areas. Understanding how these observations could translate to guanaco's species and lineage distribution will certainly contribute to the ongoing research efforts currently underway in Argentina and Chile. Hence, it is likely that efforts to expand the sampling dataset to consider guanaco's full range will also increase its climate niche definition and improve the predictions of the future distribution of the species. The work presented here represents a conservative view of guanaco's range that allows the evaluation of the evolutionary aspect of niche conservatism hypotheses based on the best knowledge of the species natural history.

\section{ACKNOWLEDGEMENTS}

The authors would like to thank PeerJ editor Bruno Marino and two anonymous reviewers for their suggestions, which contributed significantly to improve the original manuscript. 


\section{ADDITIONAL INFORMATION AND DECLARATIONS}

\section{Funding}

This work was supported by the government of Chile and CONICYT through grants Fondecyt \# 1161280, FONDEF \# D10I1038 to H. Samaniego and Doctoral Fellowship \# 21150634 to D. Alò. The funders had no role in study design, data collection and analysis, decision to publish, or preparation of the manuscript.

\section{Grant Disclosures}

The following grant information was disclosed by the authors:

Government of Chile: Fondecyt \# 1161280.

CONICYT: FONDEF \# D10I1038.

Doctoral Fellowship: \# 21150634.

\section{Competing Interests}

The authors declare that they have no competing interests.

\section{Author Contributions}

- Andrea G. Castillo performed the experiments, analyzed the data, prepared figures and/ or tables, authored first draft, and approved the final draft.

- Dominique Alò authored or reviewed drafts of the paper, approved the final draft.

- Benito A. González contributed reagents/materials/analysis tools, authored or reviewed drafts of the paper, approved the final draft.

- Horacio Samaniego conceived and designed the experiments, performed the experiments, analyzed the data, contributed reagents/materials/analysis tools, authored or reviewed drafts of the paper, approved the final draft.

\section{Data Availability}

The following information was supplied regarding data availability:

The raw data are provided in the Supplemental Files.

\section{Supplemental Information}

Supplemental information for this article can be found online at http://dx.doi.org/ 10.7717/peerj.4907\#supplemental-information.

\section{REFERENCES}

Acevedo P, Ward AI, Real R, Smith GC. 2010. Assessing biogeographical relationships of ecologically related species using favourability functions: A case study on British deer. Diversity and Distributions 16(4):515-528 DOI 10.1111/j.1472-4642.2010.00662.x.

Alvarado-Serrano DF, Knowles LL. 2014. Ecological niche models in phylogeographic studies: applications, advances and precautions. Molecular Ecology Resources 14(2):233-248 DOI 10.1111/1755-0998.12184.

Anderson RP, Raza A. 2010. The effect of the extent of the study region on GIS models of species geographic distributions and estimates of niche evolution: preliminary tests with montane 
rodents (genus Nephelomys) in Venezuela. Journal of Biogeography 37(7):1378-1393

DOI 10.1111/j.1365-2699.2010.02290.x.

Araújo MB, New M. 2007. Ensemble forecasting of species distributions. Trends in Ecology \& Evolution 22(1):42-47 DOI 10.1016/j.tree.2006.09.010.

Araujo MB, Rahbek C. 2006. How does climate change affect biodiversity? Science 313(5792):1396-1397 DOI 10.1126/science.1131758.

Araújo MB, Thuiller W, Yoccoz NG. 2009. Reopening the climate envelope reveals macroscale associations with climate in European birds. Proceedings of the National Academy of Sciences of the United States of America 106(16):E45-E46 DOI 10.1073/pnas.0813294106.

Baldi RB, Acebes P, Cuéllar E, Funes M, Hoces D, Puig S, Franklin WL. 2016. Lama guanicoe. Available at http://dx.doi.org/10.2305/IUCN.UK.2016-1.RLTS.T11186A18540211.en (accessed 17 August 2017) DOI 10.2305/IUCN.UK.2016-1.RLTS.T11186A18540211.en.

Beaumont LJ, Hughes L, Poulsen M. 2005. Predicting species distributions: use of climatic parameters in BIOCLIM and its impact on predictions of species' current and future distributions. Ecological Modelling 186(2):251-270 DOI 10.1016/j.ecolmodel.2005.01.030.

Berg MP, Kiers ET, Driessen G, van der Heijden M, Kooi BW, Kuenen F, Liefting M, Verhoef HA, Ellers J. 2010. Adapt or disperse: understanding species persistence in a changing world. Global Change Biology 16(2):587-598 DOI 10.1111/j.1365-2486.2009.02014.x.

Buisson L, Thuiller W, Casajus N, Lek S, Grenouillet G. 2010. Uncertainty in ensemble forecasting of species distribution. Global Change Biology 16(4):1145-1157

DOI 10.1111/j.1365-2486.2009.02000.x.

Collins WJ, Bellouin N, Doutriaux-Boucher M, Gedney N, Halloran P, Hinton T, Hughes J, Jones CD, Joshi M, Liddicoat S, Martin G, O’Connor F, Rae J, Senior C, Sitch S, Totterdell I, Wiltshire A, Woodward S. 2011. Development and evaluation of an Earth-System model-HadGEM2. Geoscientific Model Development 4(4):1051-1075

DOI 10.5194/gmd-4-1051-2011.

Donner LJ, Wyman BL, Hemler RS, Horowitz LW, Ming Y, Zhao M, Golaz JC, Ginoux P, Lin SJ, Schwarzkopf MD, Austin J, Alaka G, Cooke WF, Delworth TL, Freidenreich SM, Gordon CT, Griffies SM, Held IM, Hurlin WJ, Klein SA, Knutson TR, Langenhorst AR, Lee HC, Lin Y, Magi BI, Malyshev SL, Milly PCD, Naik V, Nath MJ, Pincus R, Ploshay JJ, Ramaswamy V, Seman CJ, Shevliakova E, Sirutis JJ, Stern WF, Stouffer RJ, Wilson RJ, Winton M, Wittenberg AT, Zeng F. 2011. The dynamical core, physical parameterizations, and basic simulation characteristics of the atmospheric component AM3 of the GFDL global coupled model CM3. Journal of Climate 24(13):3484-3519 DOI 10.1175/2011JCLI3955.1.

Duncan C, Chauvenet ALM, McRae LM, Pettorelli N. 2012. Predicting the future impact of droughts on ungulate populations in arid and semi-arid environments. PLOS ONE 7(12):e51490 DOI 10.1371/journal.pone.0051490.

Elith J, Graham CH, Anderson RP, Dudik M, Ferrier S, Guisan A, Hijmans RJ, Huettmann F, Leathwick JR, Lehmann A, Li J, Lohmann LG, Loiselle BA, Manion G, Moritz C, Nakamura M, Nakazawa Y, Overton JM, Townsend Peterson A, Phillips SJ, Richardson K, Scachetti-Pereira R, Schapire RE, Soberon J, Williams S, Wisz MS, Zimmermann NE. 2006. Novel methods improve prediction of species' distributions from occurrence data. Ecography 29(2):129-151

DOI 10.1111/j.2006.0906-7590.04596.x.

Elith J, Leathwick JR. 2009. Species distribution models: ecological explanation and prediction across space and time. Annual Review of Ecology Evolution and Systematics 40(1):677-697 DOI 10.1146/annurev.ecolsys.110308.120159. 
Fourcade Y, Engler JO, Rödder D, Secondi J. 2014. Mapping species distributions with MaxEnt using a geographically biased sample of presence data: a performance assessment of methods for correcting sampling bias. PLOS ONE 9(5):e97122 DOI 10.1371/journal.pone.0097122.

Franklin WL. 1982. Biology, ecology, and relationship to man of the south american camelids. In: Mares MA, Genoways HH, eds. Mammalian Biology in South America. Linesville: Pymatuning Laboratory of Ecology, University of Pittsburgh, 457-489.

Franklin J. 2009. Mapping Species Distribution. Spatial Inference and Prediction. Cambridge: Cambridge University Press.

Franklin WL, Johnson WE, Sarno RJ, Iriarte JA. 1999. Ecology of the Patagonia puma Felis concolor patagonica in southern Chile. Biological Conservation 90(1):33-40 DOI 10.1016/S0006-3207(99)00008-7.

Fuentes ER, Jaksic FM. 1979. Lizard and rodents: an explanation for their diversity in Chile. Archivos de Biología y Medicina Experimentales (Chile) 12:179-190.

Garreaud RD, Alvarez-Garreton C, Barichivich J, Boisier JP, Christie D, Galleguillos M, LeQuesne C, McPhee J, Zambrano-Bigiarini M. 2017. The 2010-2015 megadrought in Central Chile: impacts on regional hydroclimate and vegetation. Hydrology and Earth System Sciences 21(12):6307-6327 DOI 10.5194/hess-2017-191.

Gent PR, Danabasoglu G, Donner LJ, Holland MM, Hunke EC, Jayne SR, Lawrence DM, Neale RB, Rasch PJ, Vertenstein M, Worley PH, Yang ZL, Zhang M. 2011. The community climate system model version 4. Journal of Climate 24(19):4973-4991 DOI 10.1175/2011JCLI4083.1.

González BA, Palma RE, Zapata B, Marín JC. 2006. Taxonomic and biogeographical status of guanaco Lama guanicoe (Artiodactyla, Camelidae). Mammal Review 36(2):157-178 DOI 10.1111/j.1365-2907.2006.00084.x.

González BA, Samaniego H, Marín JC, Estades CF. 2013. Unveiling current Guanaco distribution in chile based upon niche structure of phylogeographic lineages: andean puna to subpolar forests. PLOS ONE 8(11):e78894 DOI 10.1371/journal.pone.0078894.

Graham CH, Ron SR, Santos JC, Schneider CJ, Moritz C. 2004. Integrating phylogenetics and environmental niche models to explore speciation mechanisms in dendrobatid frogs. Evolution 58(8):1781-1793 DOI 10.1111/j.0014-3820.2004.tb00461.x.

Guisan A, Thuiller W, Zimmermann NE. 2017. Habitat Suitability and Distribution Models: With Applications in R. Cambridge: Cambridge University Press.

Heap MJ. 2016. Introducing BioSARN-an ecological niche model refinement tool. Ecology and Evolution 6(16):5808-5816 DOI 10.1002/ece3.2331.

Hijmans RJ, Cameron SE, Parra JL, Jones PG, Jarvis A. 2005. Very high resolution interpolated climate surfaces for global land areas. International Journal of Climatology 25(15):1965-1978 DOI 10.1002/joc.1276.

Hijmans RJ, Graham CH. 2006. The ability of climate envelope models to predict the effect of climate change on species distributions. Global Change Biology 12(12):2272-2281

DOI 10.1111/j.1365-2486.2006.01256.x.

Hu J, Jiang Z. 2011. Climate change hastens the conservation urgency of an endangered ungulate. PLOS ONE 6(8):e22873 DOI 10.1371/journal.pone.0022873.

Hu J, Jiang Z. 2012. Detecting the potential sympatric range and niche divergence between Asian endemic ungulates of Procapra. Naturwissenschaften 99(7):553-565

DOI 10.1007/s00114-012-0933-1.

Hu J, Jiang Z, Chen J, Qiao H. 2015. Niche divergence accelerates evolution in Asian endemic Procapra gazelles. Scientific Reports 5(1):10069 DOI 10.1038/srep10069. 
IDE. 2016. Infraestructura de Datos Geoespaciales, Gobierno de Chile. Available at http://www.ide.cl/ descarga/capas/category/medio-ambiente.html.

Intergovernmental Panel on Climate Change (IPCC). 2013. Climate Change 2013. The Physical Science Basis. Contribution of Working Group I to the Fifth Assessment Report of the Intergovernmental Panel on Climate Change. In: Stocker TF, Qin D, Plattner GK, Tignor M, Allen SK, Boschung J, Nauels A, Xia Y, Bex V, Midgley PM, eds. Cambridge: Cambridge University Press, 1535.

Lenoir J, Gegout JC, Marquet PA, de Ruffray P, Brisse H. 2008. A significant upward shift in plant species optimum elevation during the 20th century. Science 320(5884):1768-1771 DOI 10.1126/science.1156831.

Losos JB. 2008. Phylogenetic niche conservatism, phylogenetic signal and the relationship between phylogenetic relatedness and ecological similarity among species. Ecology Letters 11(10):995-1003 DOI 10.1111/j.1461-0248.2008.01229.x.

Marin JC, González BA, Poulin E, Casey CS, Johnson WE. 2013. The influence of the arid Andean high plateau on the phylogeography and population genetics of guanaco (Lama guanicoe) in South America. Molecular Ecology 22(2):463-482 DOI 10.1111/mec.12111.

Marin JC, Romero K, Rivera R, Johnson WE, González BA. 2017. Y-chromosome and mtDNA variation confirms independent demestications and directional hybridization in South America camelids. Animal Genetics 48(5):591-595 DOI 10.1111/age.12570.

Mason THE, Stephens PA, Apollonio M, Willis SG. 2014. Predicting potential responses to future climate in an alpine ungulate: interspecific interactions exceed climate effects. Global Change Biology 20(12):3872-3882 DOI 10.1111/gcb.12641.

Merow C, Smith MJ, Silander JA. 2013. A practical guide to MaxEnt for modeling species' distributions: what it does, and why inputs and settings matter. Ecography 36(10):1058-1069 DOI 10.1111/j.1600-0587.2013.07872.x.

Meynard CN, Gay PE, Lecoq M, Foucart A, Piou C, Chapuis MP. 2017. Climate-driven geographic distribution of the desert locust during recession periods: subspecies' niche differentiation and relative risks under scenarios of climate change. Global Change Biology 23(11):4739-4749 DOI 10.1111/gcb.13739.

Moritz C. 1994. Defining "evolutionarily significant units" for conservation. Trends in Ecology \& Evolution 9(10):373-375 DOI 10.1016/0169-5347(94)90057-4.

Moss RH, Edmonds JA, Hibbard KA, Manning MR, Rose SK, van Vuuren DP, Carter TR, Emori S, Kainuma M, Kram T, Meehl GA, Mitchell JFB, Nakicenovic N, Riahi K, Smith SJ, Stouffer RJ, Thomson AM, Weyant JP, Wilbanks TJ. 2010. The next generation of scenarios for climate change research and assessment. Nature 463(7282):747-756 DOI 10.1038/nature08823.

Muñoz-Mendoza C, D’Elía G, Panzera A, Méndez T MA, Villalobos-Leiva A, Sites JW, Victoriano PF. 2017. Geography and past climate changes have shaped the evolution of a widespread lizard from the Chilean hotspot. Molecular Phylogenetics and Evolution 116:157-171 DOI 10.1016/j.ympev.2017.08.016.

Nazarenko L, Schmidt GA, Miller RL, Tausnev N, Kelley M, Ruedy R, Russell GL, Aleinov I, Bauer M, Bauer S, Bleck R, Canuto V, Cheng Y, Clune TL, Del Genio AD, Faluvegi G, Hansen JE, Healy RJ, Kiang NY, Koch D, Lacis AA, Legrande AN, Lerner J, Lo KK, Menon S, Oinas V, Perlwitz J, Puma MJ, Rind D, Romanou A, Sato M, Shindell DT, Sun S, Tsigaridis K, Unger N, Voulgarakis A, Yao MS, Zhang J. 2015. Future climate change under RCP emission scenarios with GISS ModelE2. Journal of Advances in Modeling Earth Systems 7(1):244-267 DOI 10.1002/2014MS000403. 
Pecl GT, Araújo MB, Bell JD, Blanchard J, Bonebrake TC, Chen I-C, Clark TD, Colwell RK, Danielsen F, Evengård B, Falconi L, Ferrier S, Frusher S, Garcia RA, Griffis RB, Hobday AJ, Janion-Scheepers C, Jarzyna MA, Jennings S, Lenoir J, Linnetved HI, Martin VY, McCormack PC, McDonald J, Mitchell NJ, Mustonen T, Pandolfi JM, Pettorelli N, Popova E, Robinson SA, Scheffers BR, Shaw JD, Sorte CJB, Strugnell JM, Sunday JM, Tuanmu MN, Vergés A, Villanueva C, Wernberg T, Wapstra E, Williams SE. 2017. Biodiversity redistribution under climate change: impacts on ecosystems and human well-being. Science 355(6332):eaai9214 DOI 10.1126/science.aai9214.

Peterson AT, Soberón J, Sánchez-Cordero V. 1999. Conservatism of ecological niches in evolutionary time. Science 285(5431):1265-1267 DOI 10.1126/science.285.5431.1265.

Phillips SJ, Anderson RP, Schapire RE. 2006. Maximum entropy modeling of species geographic distributions. Ecological Modelling 190(3-4):231-259 DOI 10.1016/j.ecolmodel.2005.03.026.

Phillips SJ, Dudík M. 2008. Modeling of species distribution with MaxEnt: new extensions and a comprehensive evaluation. Ecography 31(2):161-175 DOI 10.1111/j.2007.0906-7590.05203.x.

Phillips SJ, Dudík M, Schapire RE. 2004. A maximum entropy approach to species distribution modeling In: 21st International Conference on Machine Learning. Banff, 655-662 DOI 10.1145/1015330.1015412.

Pyron RA, Costa GC, Patten MA, Burbrink FT. 2015. Phylogenetic niche conservatism and the evolutionary basis of ecological speciation. Biological Reviews 90(4):1248-1262 DOI 10.1111/brv.12154.

Quevedo P, von Hardenberg A, Pastore H, Álvarez J, Corti P. 2016. Predicting the potential distribution of the Endangered huemul deer Hippocamelus bisulcus in North Patagonia. Oryx 51(02):315-323 DOI 10.1017/S0030605315001106.

Quintero I, Wiens JJ. 2013. Rates of projected climate change dramatically exceed past rates of climatic niche evolution among vertebrate species. Ecology Letters 16(8):1095-1103 DOI 10.1111/ele.12144.

Rojas M. 2012. Consultoría para la elaboración de un estudio sobre el estado del arte de modelos para la investigación del calentamiento global (Informe para Opciones de Mitigación para enfrentar el Cambio Climático, MAPS Chile).

Shrestha UB, Bawa KS. 2014. Impact of climate change on potential distribution of Chinese caterpillar fungus (Ophiocordyceps sinensis) in Nepal Himalaya. PLOS ONE 9(9):e106405 DOI 10.1371/journal.pone.0106405.

Squeo FA, Warner BG, Aravena R, Espinoza D. 2006. Bofedales: high altitude peatlands of the central Andes. Revista Chilena de Historia Natural 79(2):245-255

DOI 10.4067/s0716-078x2006000200010.

Swets J. 1988. Measuring the accuracy of diagnostic systems. Science 240(4857):1285-1293 DOI 10.1126/science.3287615.

Taylor KE, Stouffer RJ, Meehl GA. 2012. An overview of CMIP5 and the experiment design. Bulletin of the American Meteorological Society 93(4):485-498

DOI 10.1175/BAMS-D-11-00094.1.

Thomas CD, Cameron A, Green RE, Bakkenes M, Beaumont LJ, Collingham YC, Erasmus BFN, de Siqueira MF, Grainger A, Hannah L, Hughes L, Huntley B, van Jaarsveld AS, Midgley GF, Miles L, Ortega-Huerta MA, Townsend Peterson A, Phillips OL, Williams SE. 2004. Extinction risk from climate change. Nature 427(6970):145-148 DOI 10.1038/nature02121.

Thuiller W, Broennimann O, Hughes G, Alkemade JRM, Midgley GF, Corsi F. 2006. Vulnerability of African mammals to anthropogenic climate change under conservative 
land transformation assumptions. Global Change Biology 12(3):424-440

DOI 10.1111/j.1365-2486.2006.01115.x.

Thuiller W, Brotons L, Araújo MB, Lavorel S. 2004. Effects of restricting environmental range of data to project current and future species distributions. Ecography 27(2):165-172

DOI 10.1111/j.0906-7590.2004.03673.x.

Titeux N, Maes D, Van Daele T, Onkelinx T, Heikkinen RK, Romo H, García-Barros E, Munguira ML, Thuiller W, van Swaay CAM, Schweiger O, Settele J, Harpke A, Wiemers M, Brotons L, Luoto M. 2017. The need for large-scale distribution data to estimate regional changes in species richness under future climate change. Diversity and Distributions 23(12):1393-1407 DOI 10.1111/ddi.12634.

Travaini A, Donázar JA, Ceballos O, Hiraldo F. 2001. Food habits of the Crested Caracara (Caracara plancus) in the Andean Patagonia: the role of breeding constraints. Journal of Arid Environments 48(2):211-219 DOI 10.1006/jare.2000.0745.

Urban MC. 2010. Accelerating extinction risk from climate change. Science 348(6234):571-573 DOI 10.1111/1467-8322.12302.

Walther GR, Post E, Convey P, Menzel A, Parmesan C, Beebee TJC, Fromentin JM, HoeghGuldberg O, Bairlein F. 2002. Ecological responses to recent climate change. Nature 416(6879):389-395 DOI 10.1038/416389a.

Warren DL, Glor RE, Turelli M. 2008. Environmental niche equivalency versus conservatism: quantitative approaches to niche evolution. Evolution 62(11):2868-2883

DOI 10.1111/j.1558-5646.2008.00482.x.

Warren DL, Glor RE, Turelli M. 2010. ENMTools: a toolbox for comparative studies of environmental niche models. Ecography 1:607-611 DOI 10.1111/j.1600-0587.2009.06142.x.

Warren R, VanDerWal J, Price J, Welbergen JA, Atkinson I, Ramirez-Villegas J, Osborn TJ, Jarvis A, Shoo LP, Williams SE, Lowe J. 2013. Quantifying the benefit of early climate change mitigation in avoiding biodiversity loss. Nature Climate Change 3(7):678-682 DOI 10.1038/nclimate1887.

Webb CO, Ackerly DD, McPeek MA, Donoghue MJ. 2002. Phylogenies and community ecology. Annual Review of Ecology and Systematics 33(1):475-505

DOI 10.1146/annurev.ecolsys.33.010802.150448.

Wiens JJ, Graham CH. 2005. Niche conservatism: integrating evolution, ecology, and conservation biology. Annual Review of Ecology Evolution and Systematics 36(1):519-539 DOI 10.1146/annurev.ecolsys.36.102803.095431. 